\title{
Analysis of Streamline in Horizontal Well
}

\author{
WANG Guofeng \\ Daqing Oilfield Company Ltd., Daqing, China \\ 1994541@qq.com
}

Keywords: pressure ; horizontal well ; well pattern ; streamline

\begin{abstract}
In order to visually reflect the pressure distribution characteristics and the flowing tracks of reservoir fluid in five-spot horizontal well pattern, this paper obtain the pressure distribution equation of transient flow in horizontal well pattern by means of the potential superposition principle, present the calculation method of seepage field streamline, and study distribution rule for seepage field. It is shown that the seepage field of horizontal well pattern is sensitive to the horizontal permeability, horizontal well length and production time. There is a reasonable well spacing under a given horizontal permeability, which can maximize the productivity of horizontal well. The drainage area of production well will increase with the increasing of horizontal well length, which can improve the productivity of horizontal well. The streamline plots generated by this method can provide an important basis for remaining oil analysis, horizontal well pattern optimization and injection strategy.
\end{abstract}

\section{Introduction}

Exploitation technology of horizontal wells is an important technology to improve the effect of the reservoir development. Because horizontal wells increase surface area in contact with reservoir, improve the flow characteristics in reservoir, enhance oil recovery, has significant advantage than conventional vertical wells. The seepage rule of horizontal well global pattern has taken the general attention of the modern reservoir engineering recently. The seepage field can visually reflect the distribution characteristics of reservoir pressure ${ }^{[1]}$ and the flow track between the production wells and injection wells ${ }^{[2]}$, contribute to estimating the displacing area and shape, optimize the well pattern and injection scheme. Meanwhile, establishing flow streamline model can compute oil-gas field development performance ${ }^{[3]}$. Therefore, it is important to analyze the horizontal well pattern seepage field.

In the past few years, interest in studying the horizontal well seepage theory has grown tremendously, lots of researches have been obtained in analyze horizontal well seepage field. Research on seepage issue of horizontal well and vertical well unitization, however, is more than horizontal well and horizontal well unitization, which is rather complicated. In this paper, based on horizontal well seepage theory, using the potential superposition principle, the pressure distribution equation of five-spot horizontal well pattern is obtained, and the means to generate flow streamline is presented, the distribution chart of seepage field is plotted, and the influence of the reservoir permeability, horizontal well length and production time, etc. on the seepage field of five-spot horizontal well pattern is analyzed.

\section{Theoretical base}

Fig. 1 is the well location map of horizontal well pattern. It is assumed that the fluid in the reservoir is slightly compressible, and its gravitation is ignored. The horizontal well is in a laterally infinite reservoir bounded by two impermeable planes at the top and the bottom. The reservoir medium is anisotropic. The direction of coordinate axes is coordinate with the direction of reservoir principal permeability. In horizontal direction, the permeability of $\mathrm{x}$ and y orientation are $K_{\mathrm{x}}$ and $K_{\mathrm{y}}$ espectively, and in vertical direction, the permeability of $\mathrm{z}$ is $K_{\mathrm{z}}$. The horizontal well length is $2 L$. The well spacing is and the row spacing is $d$. According to the symmetrical characteristic of well pattern, the fluid 
streamline of horizontal well pattern is analyzed in quarter of well pattern unit demonstrated as shadow section (see Fig. 1).

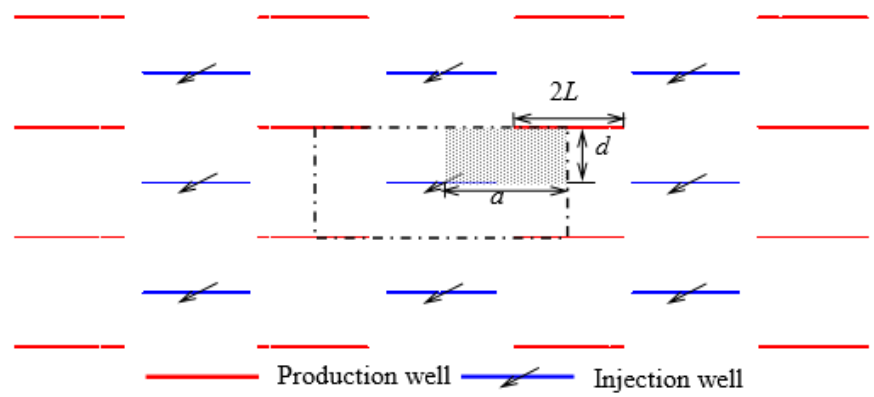

Fig. 1 Well location diagram of five-spot horizontal well pattern

On the base of the source-sink theory ${ }^{[4]}$, using Newsman product rule and pressure superposition principle, the pressure distribution equation of horizontal well pattern is expressed as

$$
\begin{gathered}
p_{\mathrm{D}}\left(x_{\mathrm{D}}, y_{\mathrm{D}}, z_{\mathrm{D}}, t_{\mathrm{D}}\right)=\frac{\sqrt{\pi}}{4} \sum_{i=1}^{m} \int_{t=0}^{t_{\mathrm{D}}} \frac{1}{\sqrt{t}} \exp \left[-\frac{\beta_{1}\left(y_{\mathrm{D}}-y_{\mathrm{wD} i}\right)^{2}}{4 t}\right] \cdot\left\{\operatorname{erf}\left[\frac{1+\left(x_{\mathrm{D}}-x_{\mathrm{wD} i}\right)}{2 \sqrt{t}}\right]+\operatorname{erf}\left[\frac{1-\left(x_{\mathrm{D}}-x_{\mathrm{wD} i}\right)}{2 \sqrt{t}}\right]\right\} \cdot \\
{\left[1+2 \sum_{n=1}^{\infty} \exp \left(-n^{2} \pi^{2} \bar{K} L_{\mathrm{D}}^{2} \beta_{2} t\right) \cos \left(n \pi z_{\mathrm{D}}\right) \cos \left(n \pi z_{\mathrm{wD} i}\right)\right] \mathrm{d} t}
\end{gathered}
$$

In Eq. (1), $p_{\mathrm{D}}=\frac{K_{e} \bar{h}\left[p_{\mathrm{i}}-p(x, y, z, t)\right]}{1.842 \times 10^{-3} q \mu B} ; t_{\mathrm{D}}=\frac{3.6 K_{x} t}{\phi \mu C_{\mathrm{t}} L^{2}} ; K_{e}=\sqrt{K_{x} K_{y}} ; \eta=\frac{K_{e}}{\phi \mu C_{\mathrm{t}}} ; \bar{h}=h \sqrt{\frac{K_{e}}{K_{z}}} ;$ $L_{\mathrm{D}}=\frac{L}{h} ; x_{\mathrm{D}}=\frac{x}{L} ; y_{\mathrm{D}}=\frac{y}{L} ; z_{\mathrm{D}}=\frac{z}{h} ; x_{\mathrm{wD} i}=\frac{x_{\mathrm{w} i}}{L} ; y_{\mathrm{wD} i}=\frac{y_{\mathrm{w} i}}{L} ; z_{\mathrm{wD} i}=\frac{z_{\mathrm{w} i}}{h} ; \beta_{1}=\frac{K_{x}}{K_{y}} ; \beta_{2}=\frac{K_{z}}{K_{x}}$.

Where $m$ is the number of horizontal wells in well pattern; $x_{\mathrm{w}}, y_{\mathrm{w}}, z_{\mathrm{w}}$ are central coordinates of horizontal well, $\mathrm{m} ; x_{\mathrm{w} i}, y_{\mathrm{w} i}, z_{\mathrm{w} i}$ are central coordinates of horizontal well $i$ respectively, $\mathrm{m} ; B$ is volume factor, dimensionless; $h$ is the effective reservoir thickness, m; $K_{x}, K_{y}, K_{z}$ are the permeability of $x, y, z$ direction respectively, $\mu \mathrm{m}^{2} ; p$ is the reservoir pressure, $\mathrm{MPa} ; p_{\mathrm{i}}$ is the initial reservoir pressure, $\mathrm{MPa} ; t$ is time, $\mathrm{h} ; \mu$ is fluid viscosity, $\mathrm{mPa} \cdot \mathrm{s} ; C_{\mathrm{t}}$ is total compressibility, $1 / \mathrm{MPa} ; \phi$ is porosity, dimensionless; $q$ is production of single horizontal well, $\mathrm{m}^{3} / \mathrm{d}$.

As the horizontal well is injection well, $q=-q_{i}$, where $q_{\mathrm{i}}$ is flow rate of injection well, and as the horizontal well is production well, $q=q_{p}$, where $q_{\mathrm{p}}$ is the flow rate of production well; injection-production ratio is defined as $R_{\mathrm{IP}}=q_{i} / q_{p}$.

According to Eq.(1), the pressure of any point in the horizontal well pattern is obtained, and then the distribution of isopiestic line can be plotted.

\section{Method of generate fluid streamline}

Doing the derivation over $x_{\mathrm{D}}$ and $y_{\mathrm{D}}$ in Eq. 1 respectively, the fluid rate of spot $j$ in $x$ direction and $y$ direction is derived as

$$
V_{x_{\mathrm{D} j}}=-\frac{K}{\mu}\left(\frac{\partial p_{\mathrm{D}}}{\partial x_{\mathrm{D}}}\right)_{j} ; V_{y_{\mathrm{D} j}}=-\frac{K}{\mu}\left(\frac{\partial p_{\mathrm{D}}}{\partial y_{\mathrm{D}}}\right)_{j}
$$

By use of Euler's method, the position of next spot $(j+1)$ can be obtained, then, the fluid streamline of horizontal well pattern is plotted.

$$
\left(\begin{array}{l}
x_{\mathrm{D} j+1} \\
y_{\mathrm{D} j+1}
\end{array}\right)=\left(\begin{array}{l}
x_{\mathrm{D} j}+\Delta s_{\mathrm{D}} \cdot V_{x_{\mathrm{D} j}} / V_{\mathrm{D} j} \\
y_{\mathrm{D} j}+\Delta s_{\mathrm{D}} \cdot V_{y_{\mathrm{D} j}} / V_{\mathrm{D} j}
\end{array}\right)+\left(\begin{array}{l}
\mathrm{o}\left(\Delta s_{\mathrm{D}}^{2}\right) \\
\mathrm{o}\left(\Delta s_{\mathrm{D}}^{2}\right)
\end{array}\right)
$$

In Eq.2, $\Delta s_{\mathrm{D}}$ denotes given step length, particle resultant velocity, denoted by $V_{\mathrm{Di}}$, is defined by

$$
V_{\mathrm{D} i}=\sqrt{V_{x_{\mathrm{D} i}}^{2}+V_{y_{\mathrm{D} i}}^{2}}
$$




\section{Analysis of fluid streamline}

Applying Eq.1, the pressure distribution schematic diagram of horizontal well pattern is computed and plotted, as shown in Fig 2. The figure indicates that the bottom hole flowing pressure of injection well is highest, and the bottom hole flowing pressure of production well is lowest. Fig. 2 shows that the pressure field distributes symmetrically, and the pressure field near each wellbore appears elliptic distribution. As approaching the bottom hole of well, the isobaric line is denser, which indicates that the pressure is significantly depleted near the wellbore.

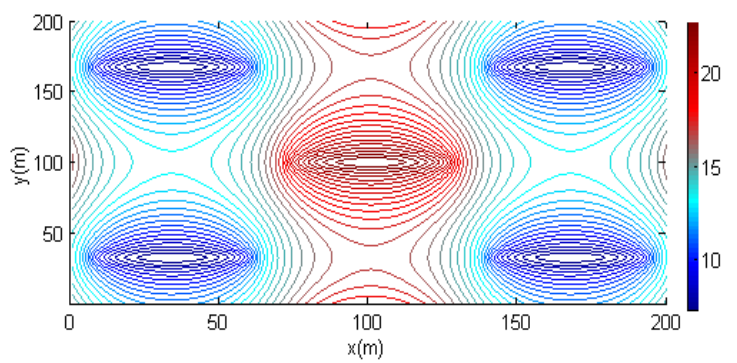

(a) Pressure isobaric line diagram

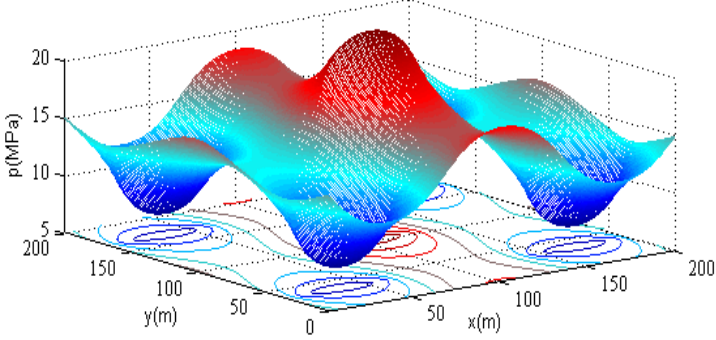

(b) Pressure cross section diagram

$$
\left(K_{\mathrm{h}}=0.005 \mu \mathrm{m}^{2} ; a=600 \mathrm{~m} ; d=250 \mathrm{~m} ; L=250 \mathrm{~m}\right. \text { ) }
$$

Fig 2. Pressure distribution diagram of five-spot horizontal well pattern

Applying Eq.2, the fluid streamline distribution schematic diagram of horizontal well pattern can be computed and plotted, as shown in Fig 3. The figure indicates that $\mathrm{x}$ axis and $\mathrm{y}$ axis affect as diversion line, the force from every direction is identical at the central position between production well and injection well, as a result, flow velocity at this position is 0 , and flow velocity of fluid nearby the central position is low too, therefore, there is dead oil area at the central position between production wells.

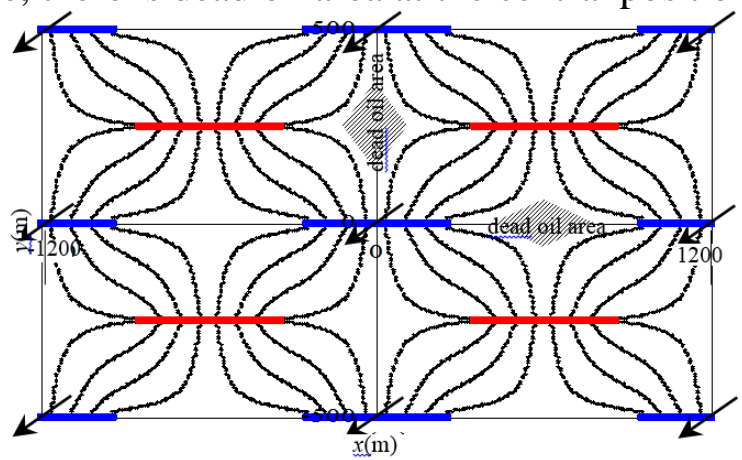

Fig 3. Streamline distribution of five-spot horizontal well pattern

The schematic diagram of fluid streamline for quarter seepage unit at different horizontal permeability is plotted, as shown in Fig 4. The figure indicates that horizontal permeability has significant influence at fluid streamline distribution of well pattern. As the horizontal permeability is low, the streamline from injection well mainly concourse at the heel of the production well, however, the streamline at the central part of the production well is rare. It indicates the production typically concourse at the two ends of production well, the sweep efficiency in waterflooding is low. We can appropriately decrease well spacing. As the horizontal permeability is high, the fluid seepage capability is higher, the streamline from injection well mainly concourse at the central part of the production well, however, the streamline at the heel of the production well is rare. The sweep efficiency of water flooding is high, and the degree of reservoir recovery is high. It indicates the production typically centralize at the central part of production well. The well spacing should be increased appropriately. Therefore, there is different optimal well spacing at different permeability to maximize the sweep efficiency of water flooding and productivity of horizontal well.

The schematic diagram of fluid streamline for quarter seepage unit at different horizontal well length, as shown in Fig. 5, is plotted. The figure indicates that, at the condition of identical well spacing, the drainage area of production well and the productivity of horizontal well increase with the increase of the length of the horizontal well. Therefore, the degree of reservoir recovery is enhanced. 
Because of the longer of horizontal well length is, however, the more the initial cost is, and the earlier water breakthrough time is. Therefore, there is an appropriate horizontal well length to horizontal well pattern.
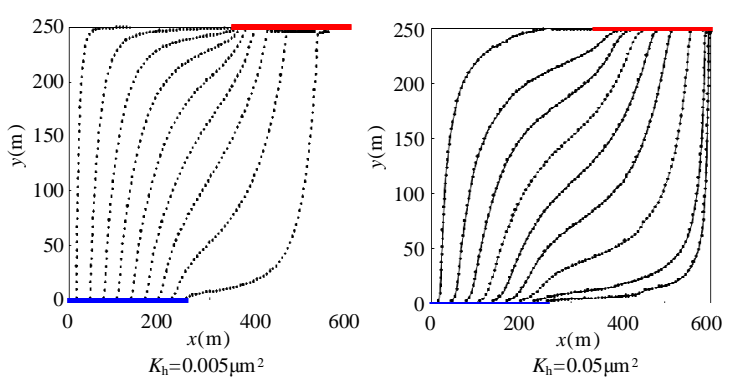

Fig. 4 Influence of permeability to streamline distribution of horizontal well pattern
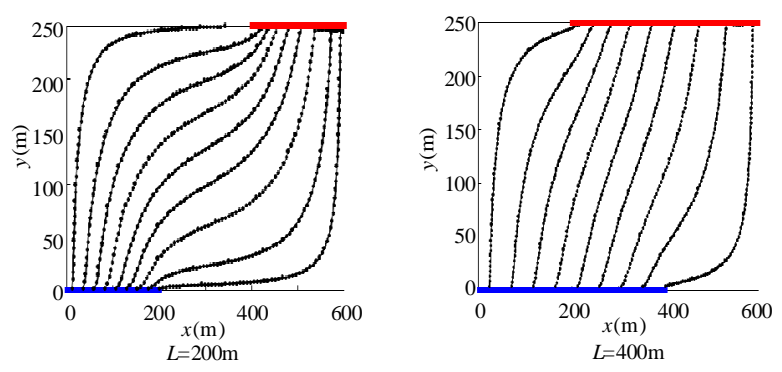

Fig. 5 Influence of horizontal well length to streamline distribution of horizontal well pattern

\section{Conclusions}

(1) The pressure distribution equation of five-spot horizontal well pattern can be obtained by applying the potential superposition principle. Based on this, the method of generating streamline is presented, and schematic diagram of seepage field distribution for five-spot horizontal well pattern is plotted. The figures show that the pressure field and the streamline distribute symmetrically, the pressure field near each wellbore appears elliptic distribution. As approaching the bottom hole of well, the isobaric line is denser, and there is a dead oil area in the central of production wells.

(2) From the analysis in this paper, it indicates that horizontal permeability and horizontal well length have significantly influenced on the seepage field of horizontal well pattern. There is a reasonable well spacing for a given permeability to maximize the water flooding efficiency and productivity of horizontal well. With the horizontal well length $(2 L)$ increasing, the drainage area of production well will be improved, thereby the productivity of horizontal well will be increased, therefore, and the reservoir recovery degree will be enhanced. The method presented in this paper can visually reflect the distribution characteristics of reservoir pressure and the flow track of reservoir fluid between the production wells and injection wells, contribute to determine the displacing area and geometry, and provide critical basis for remaining oil analysis, well pattern placement and injection strategy optimization.

\section{References}

[1] J.M. Guevara-Jordan, "A Novel Stream tube Model for Tracer Flow in an Areally Heterogeneous Reservoirs", SPE 81153, 2003.

[2] ZHOU Hongiang, YIN Hongjun, LI Meifang Study on Seepage Field of Horizontal Well Pattern in Anisotropic Reservoirs, Special Oil and Gas Reservoirs, vol.17, p. 81-84, 2010.

[3] LIU Yue-tian. Methodology for horizontal well pattern design in anisotropic oil reservoirs, Petroleum exploration and development, vol.35, p. 619-624,

[4] KONG Xiang-yan. Advanced mechanics of fluids in porous media, University of Science and Technology of China Press, 1999. 